\title{
Development of an Assessment Strategy for Urban Regeneration Projects in Historic City Centres in Iraq
}

\author{
Aqeel Q. Al-Mosawi ${ }^{1,2}$ \\ ${ }^{1}$ Department of Urban Design and Land Use Planning, Faculty of Spatial Planning, TU Dortmund University, \\ Germany \\ ${ }^{2}$ Faculty of Engineering, University of Kufa, Iraq \\ Correspondence: Aqeel Q. Al-Mosawi, Fakultät Raumplanung, Technische Universität Dortmund, August- \\ Schmidt-Str.10, 44221 Dortmund, Germany. E-mail: aqeel.al@tu-dortmund.de
}

\author{
Received: September 3, 2017 Accepted: October 9, $2017 \quad$ Online Published: November 29, 2017 \\ doi:10.5539/jsd.v10n6p87 \\ URL: https://doi.org/10.5539/jsd.v10n6p87
}

\begin{abstract}
In the Iraqi context the importance of urban regeneration in improving the conditions of the physical environment is still not recognized. Furthermore, the rise of urban regeneration initiatives in Iraq due to the deterioration of the physical urban heritage in Iraqi cities, leads to raising the questions about the level of success of these initiatives in finding sustainable solutions to the urban problems with regard to heritage conservation. The current study attempts to develop a suitable assessment strategy for local regeneration projects and to explore possible alternatives which can assist in reorienting urban design strategies towards more sustainability based on assessment of the urban design aspects against a set of performance criteria and indicators.

The study argues that urban design is integral to the process of urban regeneration achievement and assessment; through identifying the relationship between urban design principles and sustainable development objectives in the regeneration practises. Based on that, indicators were identified to form the skeleton of the assessment strategy to measure the performance of urban regeneration at the local level. These indicators underwent a detailed evaluation process, with the help of local experts. The research methodology and findings would enrich the related academic fields and will help to strengthen the understanding of urban designers and local stakeholders on how to plan sustainable regeneration projects and create sustainable communities. To ensure that the derived strategy is theoretically and practically feasible, an urban regeneration project as case study was selected and assessed against individual indicators.
\end{abstract}

Keywords: historic city centres in Iraq, role of urban design in urban regeneration process, sustainable urban regeneration, urban design

\section{Introduction}

Different initiatives have been implemented in order to revitalize the declining city centres and many countries have tested various methods and policies to use sustainable urban conservation as a useful strategy for urban redevelopment and one of these policies is the regeneration. According to Tallon (2013, p.3) urban regeneration policy has become widely used as an urban transformation strategy in many cities and has been given an increased public profile within the urban policy agenda since the 1990s. Kühn and Liebmann (2012) mentioned that the regeneration of cities is a complex process including demographic, physical and socio-economic dimensions. A well-known definition of urban regeneration by Roberts and Sykes (2000, p.17) which emphasizes the interplay of different dimensions of urban problems, "Comprehensive and integrated vision and action which leads to the resolution of urban problems and which seeks to bring about a lasting improvement in the economic, physical, social and environmental condition of an area that has been subject to change".

The gradual destruction of the urban heritage context in the Iraqi cities, concurrently with the particular set of problems that face the rehabilitation of urban heritage values as a result of lack of national planning policies, development strategies and lack of socio-political awareness, led to the rise of urban regeneration initiatives in Iraq in the last decade. This raises the questions about:

- The level of success of these projects and how far they are successful in terms of reversing the physical, social and economic decline, and finding comprehensive solutions to the urban problems.

- How can the physical dimensions of urban regeneration projects in historic city centres in Iraq be oriented towards more sustainability? 
The current study focuses on these queries and the analytic framework will be formed by linking the concepts of sustainable redevelopment, urban regeneration and urban design. Furthermore a number of issues need to be investigated such as:

- Urban design is an essential facilitator in sustainable urban regeneration, allowing the incorporation of more sustainable attributes from physical, economic and social perspectives in the process.

- The methods and process of the assessment will identify the design criteria being highlighted in the projects to evaluate the effectiveness of these projects.

Based on the above, the objective of this study is to develop an assessment strategy for urban regeneration projects at the local level, and the expected outcome is a conceptual framework that suggests an assessment model for the sustainability of urban regeneration projects. The strategy will be evaluated in the empirical part of the research by a case study. Due to the limitations of the study and multidimensional theme of sustainable urban redevelopment concept, the study focused mainly on the physical aspects of this concept and its application to the local context, bearing in mind that the dimensions of sustainability are connected and interrelated.

\section{Theoretical Background}

\subsection{Linking Urban Regeneration and Sustainability}

There are clear interrelationships between redevelopment and sustainability issues, which have been increasingly incorporated within urban regeneration policies (Tallon, 2013, p.179). As mentioned by Chanan, West, Garratt and Humm (1999) the promotion of city centre living that meet the sustainability goals, as well as supporting economic regeneration, has been a key objective of urban regeneration policies and indicates how the dimensions of regeneration and sustainability are closely interrelated. Department of the Environment, Transport and the Regions [DETR] (2000); Jones and Evans (2008, p.86) outlines the key dimensions of sustainable regeneration that were set out in the Urban White Paper (table 1), they emphasized that while the elements of sustainable regeneration are categorised as environmental, economic and social, it is clear that in practice each element of sustainability is addressed by more than one regeneration goal. The Urban White Paper makes strong links between the ideas of 'mixed' and 'sustainable' communities, which is a key element in achieving sustainable regeneration.

Table1. Key elements of sustainable regeneration

\begin{tabular}{|c|c|c|c|}
\hline $\begin{array}{l}\text { Element } \\
\text { sustainability }\end{array}$ & of & Goal & Reason \\
\hline \multirow{3}{*}{\multicolumn{2}{|c|}{ Environmental }} & $\begin{array}{l}\text { Re-use derelict land for high- } \\
\text { density development }\end{array}$ & Protect countryside and decrease car use \\
\hline & & Improve environmental quality & Enhance quality of life and attract investment \\
\hline & & Use energy efficient buildings & Decrease ecological footprint of urban areas \\
\hline \multirow{2}{*}{\multicolumn{2}{|c|}{ Economic }} & Rejuvenate housing stock & Revitalise city centres \\
\hline & & $\begin{array}{l}\text { Attract development and create } \\
\text { jobs }\end{array}$ & Improve local economy \\
\hline \multirow{3}{*}{\multicolumn{2}{|c|}{ Social }} & Mixed-use developments & $\begin{array}{l}\text { Decrease car use (live, work and play in same } \\
\text { area) }\end{array}$ \\
\hline & & Mixed communities & Increase social integration \\
\hline & & Inclusive decision-making & $\begin{array}{l}\text { Respond to local needs and increase social } \\
\text { capacity }\end{array}$ \\
\hline
\end{tabular}

Source: Jones and Evans (2008, p.87)

According to Jones and Evans (2008, p.86) the goals in table (1) identify factors such as energy efficiency in construction as critical in combating fuel poverty; local environmental action as a mechanism to create jobs and promote re-investment; green transport plans to improve public transport, cycling and walking facilities. Lee (2008, p.100) points out that promoting sustainable development in the urban area is one of the major objectives of urban renewal and that design principles for achieving sustainability in the territory is required. It is clear from the points above the strong relationship between urban regeneration and sustainability; moreover an assessment of the effects of urban regeneration policy also reveals linkages with sustainability.

\subsection{Urban Regeneration Assessment and the Role of Urban Design}

Devuyst (2001, p.9) explained the assessment as a tool that can be used by decision-makers and policy-makers to decide which action they should and should not take in an attempt to make society or their cities more sustainable. According to School of the Built Environment-Napier University [SBE] (2005, p.9) implementing 
urban regeneration assessment should encourage decision-makers to give appropriate attention to sustainability issues and lead to the production of information that can be used in planning as well as raising public awareness. To link these objectives with the decision-making processes, tools and indicators for measuring progress are also required, along with regeneration procedures. As mentioned by Hemphill, Berry and McGreal (2004) the evaluation frameworks of urban regeneration follow an indicator-based approach by including contextual measures to identify the baseline assessment of the area, the conditions within which the strategy is operating and the effects of policy actions.

DETR (2000, p.9) pointed out that the best way to promote successful regeneration is to think about urban design from the beginning of the development process. The need for integrative approach in regeneration leads to questions about the possibilities of urban design to become an integrative instrument. Mrdenovic (2011, p.305) highlighted that nowadays urban design is challenged by the contemporary concept of regeneration, and in relation to socioeconomic transition process, as one of the specific conditions of urban regeneration context. This process re-affirms urban design as an initiator of regeneration approach, where urban design practice is an integrative process of urban production. Furthermore the multidimensional process of urban design can provide creative solutions for different sectors of sustainable regeneration.

\subsection{Value of Urban Design}

According to Commission for Architecture and the Built Environment [CABE] and DETR (2001) Urban design is the art of making places for people, it includes the way places work and how they look. It concerns the connections between people and places, movement and urban form, nature and the built fabric. Urban design is a key to creating sustainable development and the conditions for a flourishing economic life, for the prudent use of natural resources and for social progress. Good design can help create lively places with distinctive streets and public spaces that are safe, accessible, pleasant to use and human in scale. A study by Lee (Lee, 2008, p.49, 100) referred to urban design as "the art of shaping physical urban environment, preserving nature and built fabric with unique features, satisfying needs of the people". The study looked into 6 key urban design principles, taking into account the attributes and special regeneration need of historic environments, namely: compact design and intensive development, proper mix and balance of land uses, establishment of inter and intra-regional linkage, respect for positive identity, plan for comfort and quality living and maximization of community participation.

It is believed that urban design can achieve sustainable urban regeneration by changing existing built environment with due consideration to the economic, social and environmental agendas in the planning process.

\section{Theoretical Framework for Selection of the Urban Design Principle}

Previous studies have stressed a number of areas that should be considered during the urban design process for enhancing the sustainability of urban regeneration projects, for example Colantonio and Dixon (2011) identified five dimensions of urban sustainability: Economic, Social, Environmental, Physical and Cultural. According to CABE (2003, p.7) the physical expression of urban design is one of the sustainable development forms, which consist of the relationships, shape and size of buildings, structures and spaces, which is fundamental to the success of a place. With reference to these studies, a number of design principles contributing to sustainable development can be identified for relevant urban design considerations. Colantonio and Dixon (2011, p.34) introduced the framework for sustainability assessment against social criteria at multiple levels as shown in figure (1). The framework illustrates how the overarching milestones of social sustainability are guided by four principles and policy actions. These principles provide guidelines to achieve sustainability in seven themes, ranging from 'living' to 'moving'. Indeed, a guide to the implementation of the framework, identifies the characteristics required to 'live', 'work', 'play' and so on in an equitable, inclusive, safe and adaptable way.



Figure 1. Framework for social sustainability assessment in Vancouver

Source: Colantonio and Dixon (2011, p.34). 
As mentioned by Holden (2006) the interrelationships between principles and themes, underpin the progress towards sustainability, this progress is monitored through a set of urban sustainability indicators that draw upon expert or citizen-based recommendations. Based on the framework in figure (2) the basis for developing a physical sustainability assessment strategy for the city centres in Iraq can be formed, the hierarchy of framework including; Theoretical (approaches), Policy (principles and objectives) and Practical (methods and indicators). Examining the physical sustainable principles and indicators of urban design will set up the strategy for the evaluation of urban regeneration projects in Iraqi historic cities.



Figure 2. Urban sustainability assessment frameworks

Source: modified from Colantonio and Dixon (2011, p.216)

\subsection{Identification of the Key Urban Design Objectives and Principles}

CABE and DETR (2001, p.17) pointed out that the design of the built environment is faced by two problems; first, defining the scope and nature of good urban design and second, making objective judgements about the relative merits or otherwise of particular design solutions. Analyses of these factors would produce principles or objectives of good urban design and considerable overlap between them will help to create successful places. Wansborough and Mageean (2000, p.188) identified several urban design concepts which focus on the processes by which the built environment is created and which are synergic with the components of cultural strategies. The design guidelines published by DETR (2000) indicated 8 main aspects that define the physical form of development fulfilling the urban design principles to create a successful place, these are: own identity; attractive and successful outdoor areas; variety and choice; distinguished public and private spaces; easy to get to and move through; a clear image and easy to understand; and that can change easily.

The current study developed its framework from a combination of existing assessment models, which focused mainly on the physical aspects of built environment. Accordingly a number of urban design principles contributing to the physical and visual sustainable urban development were identified. Figure (3) shows the theoretical framework for selecting the appropriate urban design principles that are adopted for the current study and the key principles are set out, as shown in table (2). These principles are not definitive but represent the important typical design variables or objectives extracted from the literature. They are emphasised in broad design principles published in various design standards and establish a benchmark requirement of the design quality expected from the new regeneration. In addition they inform the need to deliver a sustainable design, with a complementary relationship to the historical context and refurbishment of an existing urban area. 


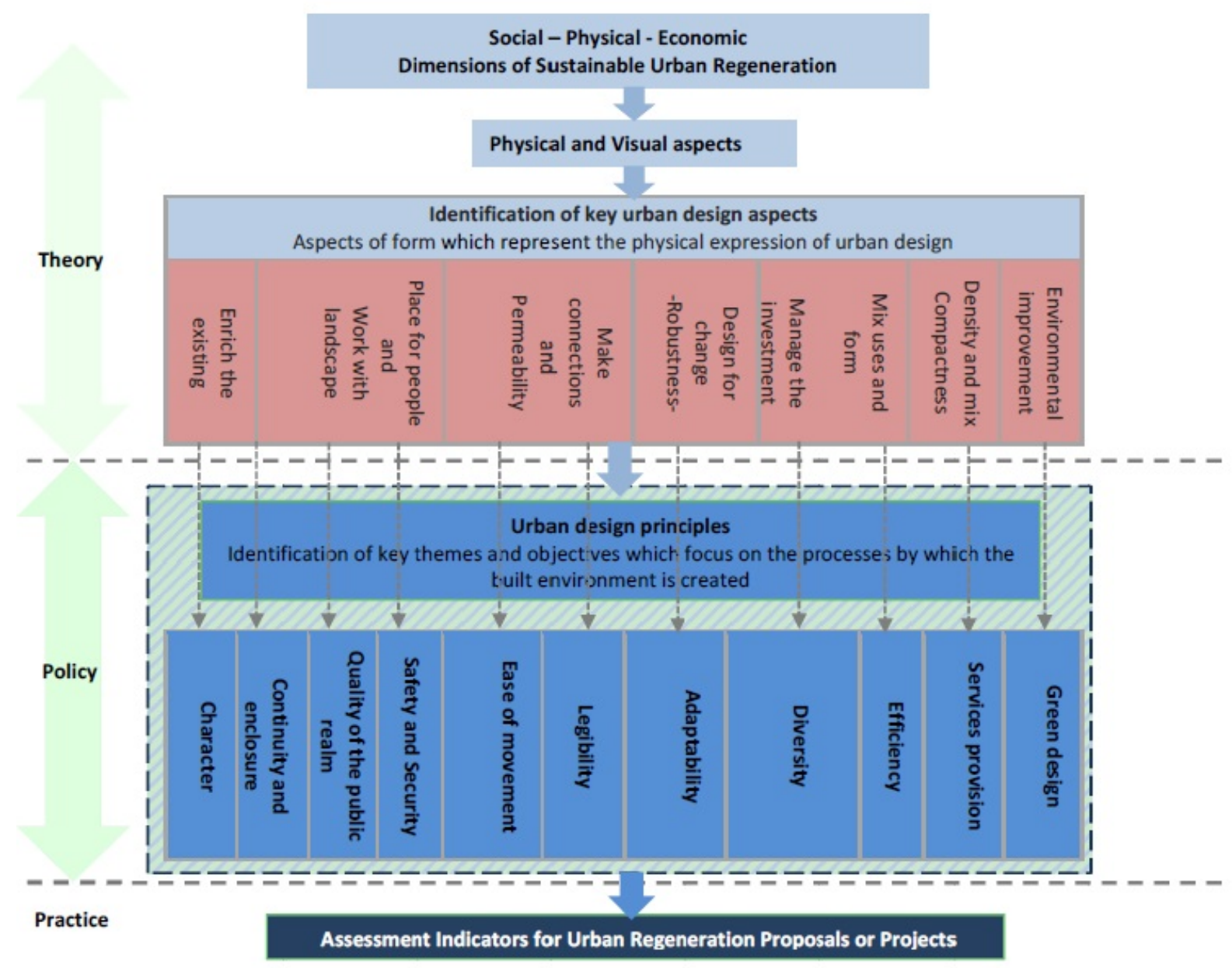

Figure 3. Theoretical framework for selecting the urban design principles

Source: author construct based on: DETR, 2000; CABE and DETR 2001; Llewely and Baxter, 2007; Lee, 2008.

Table 2. Urban design principles adopted in the current research and their definitions

Urban design principles
Character: Sense of place and history
Refers to the place identity. It aims to promote character in townscape and landscape by
development that responds to and reinforces locally distinctive patterns of development,
landscape and culture.
Continuity and enclosure: Clarity of form
Refers to the places where public and private spaces are clearly distinguished. It aims to
promote the continuity of street frontages and the enclosure of public spaces which are
visually defined by buildings and other elements.
Quality of the public realm: Sense of wellbeing and amenity
Refers to the places with attractive, lively and successful outdoor spaces and routes. It aims
to promote public spaces that are safe and work effectively for all in society to maximize
community participation and to plan for comfort and quality living.

Ease of movement: Connectivity and permeability

Refers to the place that is easy to get to and move through, also convenient, efficient and safe environment for pedestrians and public transport users. It aims to promote physical and visual accessibility and permeability by integrating land uses and transport.

Legibility: Ease of understanding

Refers to the spatial structure of place that has a clear image and is easy to understand as a whole. It aims to promote legibility through development that provides recognisable routes, intersections and landmarks to help people find their way around.

Adaptability: Ease of change

Refers to the place that can change easily and the degree of rehabilitation of repairable properties. It aims to promote adaptability through development that can respond to changing social, technological and economic conditions.
References that highlighted the principles

DETR, 2000; CABE, 2003;

Llewelyn \& Baxter, 2007;

RBC, 2007; Lee, 2008;

Llewellyn et al., 2008

DETR, 2000; CABE, 2003;

Ewing et al., 2005; Lee, 2008

; Llewellyn et al., 2008

DETR, 2000; Wansborough \& Mageean, 2000; CABE, 2003; RBC, 2007; Lee, 2008; Llewellyn et al., 2008

DETR, 2000; Ewing et al., 2005; RBC, 2007; Lee, 2008; Llewellyn et al., 2008; Biddulph, 2011

DETR, 2000; CABE, 2003; Ewing et al., 2005; NHDC, 2007; RBC, 2007; Llewellyn et al., 2008

DETR, 2000; CABE, 2003; RBC, 2007; Lee, 2008; Llewellyn et al., 2008 
Diversity/ Complexity and Ease of choice

Refers to the place with variety of choices and mixed uses. It aims to promote compatible developments and uses that to create viable places which respond to local needs. Complexity refers to the visual richness of a places and physical environment.

\section{Efficiency: Green construction}

Refers to the appropriate use of resources, including mix and balance of land use. It is about construction measures that use energy and other natural resources in an effective and efficient way such as reuse and recycling of materials; use of renewable materials, to minimise environmental demands and ensure efficient conversion.

\section{Safety and Security: Sense of safety}

Refers to the places that are safe, secure, and welcoming. It is a vital element in any urban redevelopment and the integrated design is an important instrument in enhancing the sense of well-being and making places more user-friendly, easy to understand and secure.

Services provision: Compactness and access to public facilities

Refers to an appropriate and high quality infrastructure and the possibility of approaching the public facilities that are essential to support the daily requirements of the community, for example; buildings or systems used for educational, medical, recreational and cultural purposes.

Green Design: Reduce the impact of development on climate change.

It refers to the design that optimizes the use of natural resources such as sunlight and air movement through the appropriate orientation, use of thermal mass or proper window placement to minimize the consumption of natural resources or use them in an effective and efficient way.

Source: Author elaboration.

\subsection{Identification of Urban Design Assessment Indicators}

Urban sustainability indicators identified by Science for Environment Policy [SEP] (2015, p.5) are tools that allow planners, and policymakers to gauge the socio-economic and environmental impact, for example, current policies, urban designs and infrastructures. They allow for the diagnosis of problems and monitor the success and impact of sustainability interventions. DETR (1998) highlighted that the indicators must be technically robust, easily understood, sensitive to change, measurable and capable of being regularly updated. Hemphill et al. (2004) illustrated a four-step procedure in determining the selection and derivation of indicators on a systematic basis as shown in figure (4).

\begin{tabular}{|c|} 
Conceptual consolidation \\
Clarify the basic concepts to be represented in the analysis \\
\hline Analytical structuring \\
Providing a structure within which the indicators can be collated \\
\hline Indicator identification \\
Translation of the analytical structure into specific measurable indicators \\
\hline \\
Process of synthesising the proposed indicators into a single/composite measure \\
\hline
\end{tabular}

Figure 4. Indicators selection approach

Source: Hemphill et al. (2004)

Llewellyn et al. (2008) identified 12 questions to encapsulate the range of urban design considerations by extraction of urban design and sustainability principles. These questions can be used as a basis for structuring design and to structure pre-planning negotiations between applicants and planning authorities or serve to foster a more collaborative approach between stakeholders towards a common objective of optimal design solution. In the current study these questions are translated into the 15 assessment criteria (table 3) that have been linked with the main urban design principles. By articulating urban design principles and assessment criteria, the current research sets out the key assessment indicators of the physical form of development in the historic built 
environment as shown the final structure of urban regeneration assessment strategy in Appendix (A). The final form of the assessment model show how the urban design elements can be utilised to form the assessment strategy in the planning process.

Table 3. Questions that frame the range of urban design considerations and associated design criteria

\begin{tabular}{lll}
\hline & Questions that frame the urban design considerations & Related criteria \\
\hline 1 & How does the development respond to its surroundings? & Context \\
\hline 3 & How well connected is the new neighbourhood? & Connections \\
\hline 4 & How easily can people use and access the development? & Inclusivity \\
\hline 5 & How does the development promote a good mix of activities? & $\begin{array}{l}\text { Variety } \\
\text { Compactness }\end{array}$ \\
\hline 6 & How does the development make appropriate use of resources, including land? & $\begin{array}{l}\text { Efficiency } \\
\text { Green design }\end{array}$ \\
\hline 7 & How does the proposal create a sense of place? & Distinctiveness \\
\hline 8 & How safe, secure and enjoyable are the public areas? & Layout \\
\hline 9 & How will the buildings cope with change? & Public Realm \\
\hline 10 & How does the scheme provide a decent standard of amenity? & Sense of safety \\
\hline 11 & How will the parking be secure and attractive? & Adaptability \\
\hline 12 & How well thought through is the building and landscape design? & Privacy and Amenity \\
\hline Sourdeen & Open spaces and Parking \\
\hline
\end{tabular}

Source: Summarised from Llewellyn et al. (2008).

\section{Structure of Urban Regeneration Projects Assessment Strategy}

The developed assessment framework in the present research was achieved by establishing clear criteria against which judgements on urban design quality requirements could be made. This has been used for establishing a more holistic classification system for sustainability indicators in the evaluation of the built environment at a local planning level and developing an integrated framework for evaluating urban regeneration in the context of sustainability.

The main components of assessment model are the identified urban design criteria and their associated assessment indicators. In the current research, the issue of setting a suitable benchmark is based upon the scoring system in order to formulate the final form of developed assessment strategy (See Appendix. A). The performance of urban regeneration projects is evaluated by grading individual assessment indicators, and a series of points are allocated for these indicators, to facilitate the assessment of the projects in terms of urban design. Based on the qualitative nature of adopted indicators, the ordinal scales were mainly employed when devising the scoring system. The study adopted Likert-type scale for evaluation of the regeneration projects at local level. In the final form of the assessment strategy, each indicator is capable of scoring 5 points. The indicators that represent the urban design criteria are described by a single sentence indicating the appropriate way to achieve sustainable urban regeneration.

\section{Methodology and Implementation}

The urban design principles, key criteria and assessment indicators which represent the main components of assessment strategy, have been derived and modified from the literature and guidance presented by urban design strategies and cultural heritage redevelopment policies. To examine the validity and reliability of the developed assessment strategy, this appraisal framework is applied to a selected case study, which is representative of the contemporary urban regeneration initiatives employed recently by the urban authorities in Iraq. Therefore the study employs the case study methodology.

Structured questionnaires survey were used mainly in the study with mixed questionnaires in some parts to obtain the opinions of local experts (main stakeholders, planners, architects, urban designers) on the extent of implementation of the developed assessment strategy at the local level and to evaluate the validity of the proposed model to assess the regeneration proposals or projects. The data collected from the questionnaire has been used to support and modify the design of the developed assessment strategy to evaluate urban regeneration initiatives in aspects of physical and cultural heritage values in a sustainable manner. The case study as a largescale urban design proposal has been assessed according to the developed model and the assessors was asked to evaluate the urban policies and design strategies of the regeneration proposal, according to the main aspects or design principles that are mentioned in assessment strategy. 


\section{Case Study}

\subsection{Contemporary Urban Regeneration Initiatives in Iraq}

since 2004 the Iraqi government, represented by the Iraqi Ministry of Municipalities and Public Works (MMPW) - Directorate General of Physical Planning (DGPP) has been actively working to develop sustainable master plans for the cities of Iraq, as a part of efforts to reconstruct the country after the war in 2003. These programmes are still continuing as part of urban regeneration projects being undertaken by the government, especially in the historic cities. The main goals of these programmes and projects include redesigning the master plan of these cities and regenerating the urban fabric of the historic cities that have been neglected for many decades. These historic city centres face serious crises because of the overloading of their delicate fabric with the vast numbers of visitors especially in the religious sites, therefore the regeneration initiatives aims to ensure that the accommodations and public facilities are able to cope with the volume of visitors, in addition to ensuring that these areas remain vibrant and attractive for residents throughout the day and year.

The urban regeneration project of Najaf city center that was proposed by Dewan in 2015 was selected as a case study for current investigation and for application of the developed assessment strategy. The project was selected because it was felt that it could provide a good example for evaluation of the urban redevelopment practices at the national level and exemplify the lessons learned from local regeneration approaches and furthermore to evaluate the effectiveness of the developed assessment strategy.

\subsection{Case Study Definition}

The city of Najaf has been selected in the current research owing to its significant historical, religious and cultural nature. It is one of the important cities in the central part of Iraq, located $160 \mathrm{~km}$ to the south of Baghdad; figure (5) show the regional connections of city. Najaf is the place of the shrine of Imam Ali bin Abi Talib (cousin of Prophet Muhammad) (Dumper, 2007, p.268). Numerous mosques, schools and libraries were built around the shrine to make the city the centre of learning and worshiping. The city will be examined as an urban unit, discussing its overall plan and its urban form. When studying the urban features of Najaf city, it is important to distinguish the traditional walled city, around the shrine (figure 8) from the sprawling new city that has spread outside its walls and is linked with kufa city (figures 6,7). There is a clear difference between the two parts of the city in terms of continuity; they differ in plan, urban form, built form and social organization. The research will focus on the old walled city of Najaf and its regeneration initiatives. The walled city had an irregular circular shape, with a circumference of around $3 \mathrm{~km}$ and a maximum length from east to west and from north to south of no more than $900 \mathrm{~m}$. According to Tabbaa and Mervin (2014, p.46) Najaf's defensive wall was pierced by four main gates and its trace is clearly visible today as a vacant strip that has been taken up by a ring road. Like most other Islamic historical cities, all the main roads led to the prominent centre of the city, namely the shrine. The city is divided into four quadrants by traditional thoroughfares with the shrine in the central position (figure 6). These have been considerably expanded into broad streets and markets in recent years. Leading from the shrine to the original city gates, four residential quarters of intramural Najaf are contained between the main streets, which are: Al-Mishraq, Al-Amara, Al-Huwaysh and Al-Buraq, The fifth sector of the city is the Grand Bazaar.

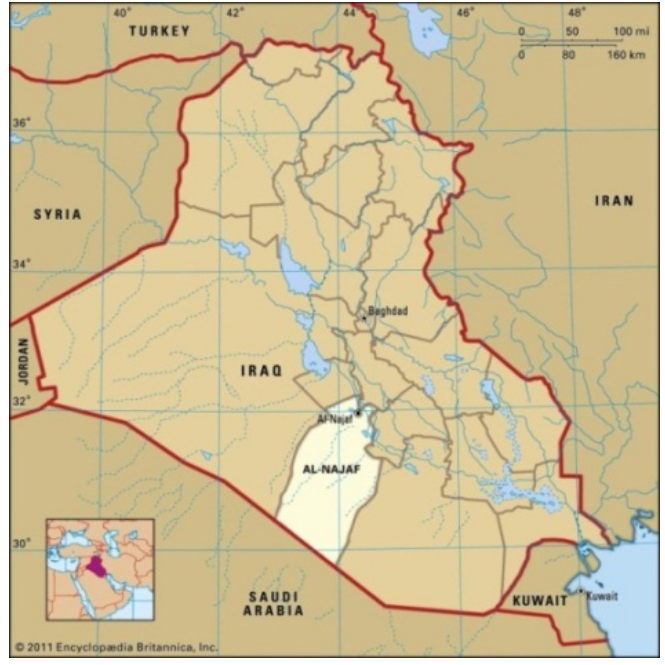

Figure 5. Najaf location map

Source: Encyclopaedia Britannica, 2011: https:/www.britannica.com/place/AlNajaf/images-videos/Al-Najaf-capital-of-AlNajaf-governorate-Iraq/160075

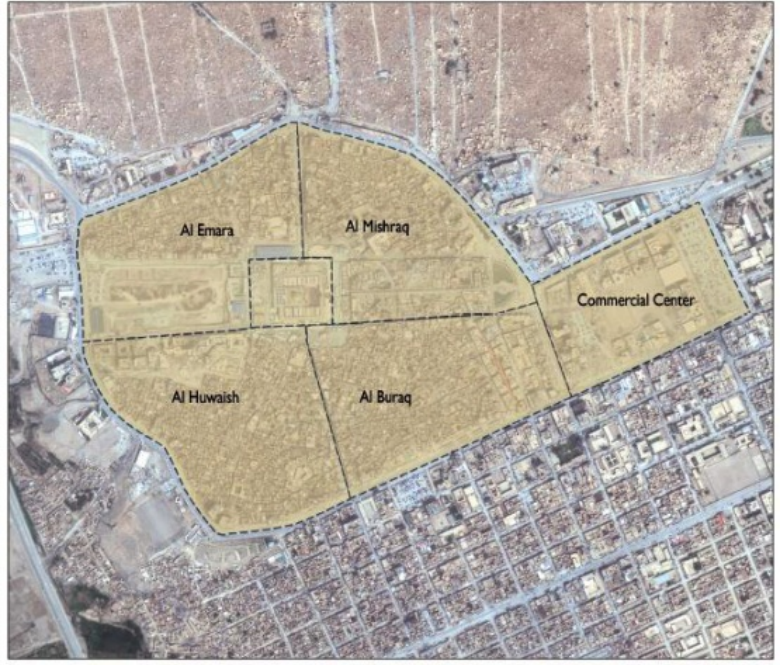

Figure 6. Neighbourhoods of the old city of Najaf (study area)

Source: Dewan (2015, p.5) 


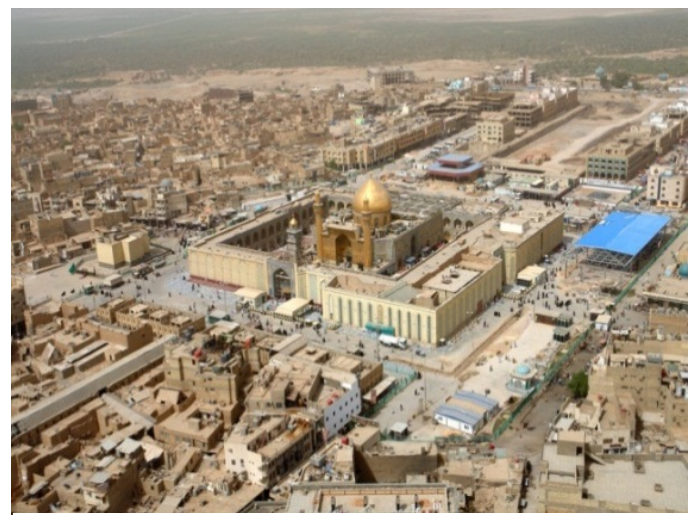

Figure 7. Shows urban fabric around the shrine (2010) after recent transformation in the city structure

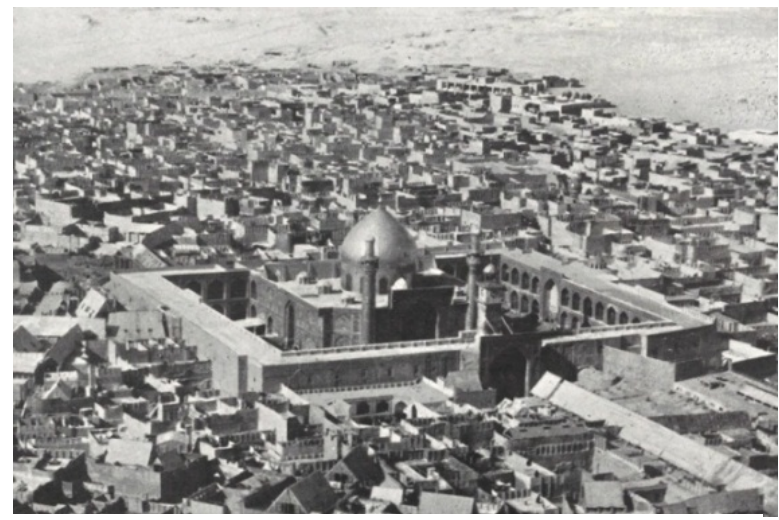

Figure 8. The old coherent urban fabric of Najaf city, around the shrine (first half of 20th century)

Source: architectural-review.com

\subsection{Urban Regeneration Project of Najaf Historic City Center}

Updating the master plan of historic city centre of Najaf was part of an urban regeneration project being undertaken by the Iraqi Government. In 2010 Dewan (Architects \& Engineers) were awarded consultancy contracts to prepare the regeneration proposal of the old historic core of Najaf city. The overall aim of this project is to revitalise, regenerate and adapt the urban fabric of the old city to contemporary demands, at the same time emphasising its historical identity (Dewan, 2010). The project objectives that were proposed by the client and as mentioned by Dewan (2015) can be summarised as following:

- Rehabilitation and reconstruction of the urban fabric of the old city with enhancement of the historical and cultural identity.

- Developing the area around the shrine to cope with the emerging socioeconomic and physical changes and to provide adequate spaces that are necessary to accommodate huge numbers of visitors.

- Maintaining and rehabilitating the buildings with heritage values in the historic part and determining the conservation policy such as: conservation, maintenance, renewing, etc.

- Improving the urban environment by creating suitable open spaces to serve the residents and visitors and renewing the social and services infrastructure.

- Enhancing social and cultural activities and improving the economic situation by creating sustainable investment opportunities for the city.

- Encouraging community participation in the policy making, planning and implementing stages of the regeneration project.

\subsubsection{Planning Policies and Site Obstacles}

Based on the project reports that were prepared by the consultants, the following points can be highlighted regarding the planning policies and site obstacles which were taken into account throughout design the project:

- The study area contains a range of projects that have been proposed and approved by the client in advance. These projects were taken in consideration in the design process, especially the aspects related to land uses schedule and buildings heights recommendations, in order to achieve compatibility with the existing fabric.

- The study area and the outskirts face many considerations regarding future expansion and provision of land for the increasing demand for public services. According to the site features, it is obvious the limited options of suitable areas to accommodate future growth as public facilities.

- The study areas were divided by the consultants according to the following main administrative divisions: 1 . Holy Shrine zone (Ataba), 2. Al-Mishraq Neighbourhood, 3. Al-Buraq Neighbourhood, 4. Al- Huwaysh Neighbourhood, 5. Al-Amara Neighbourhood, 6. Grand Suq Area (Grand Bazar).

\subsubsection{Planning Policies and Design Strategies}

The urban regeneration strategies of the project are in several aspects, as follows:

\section{Strategy 1: Cultural heritage conservation and regeneration regulations}

After surveying and assessing the existing buildings in the old historic urban fabric by the consultant team as 
shown in figure (9), rehabilitation strategies were determined to deal with these properties according to their heritage values and structural status. Four strategies were proposed, as follows (Dewan, 2015, p.75):

1- Buildings with high value (type A): which are in a good condition, preserved on the same building style and enhancement their importance by redesigning the spaces surrounding them.

2- Buildings with medium value (type B): include the buildings that need to be rehabilitated in a way similar to the original heritage style and to be integrated within the urban fabric. Creating a large heritage complex must take in consideration the ability to use it as an investment heritage site and utilize it with suitable activities.

3- Buildings with Low value (type C): these buildings can be rebuilt in the same traditional form or in different style depending on their moral values and they can be rebuilt in the existing place, or it can be relocated to other locations if necessary.

4- Buildings with no heritage value (type D): these are mostly without any relevant historical or architectural significance. These buildings can be relocated or removed.

\section{Strategy 2: Land Use Policy}

The provision of sufficient spaces to accommodate the huge numbers of visitors is the main challenge for land uses policy of the old city of Najaf. According to Dewan $(2015$, p.6) the major challenge of the proposal was how to provide enough space around the shrine to cope with the movement of visitors in conjunction with preservation of the traditional fabric of the city as much as possible in order to maintain urban identity. The proposed land uses for the historical core (figure 10) can be addressed in different levels as following:

- Expansion of the area surrounding the shrine was introduced, between $85 \mathrm{~m}-90 \mathrm{~m}$ starting from outside the wall of shrine courtyard, with preservation of buildings with distinctive heritage values within this range.

- The above mentioned area has been identified by a corridor separating it from the rest of the land uses. The area surrounding the corridor is generally commercial services.

- After this commercial area, there will be residential districts in addition to the lodges that serve tourists in the days of mass visits.

- The area along Al-Muheet Street has mixed use (residential/commercial), including hotels, retail and offices. This will formulate the transition area between the traditional part and the rest of the city.

- Regarding the Grand Bazar (Suq), the retail merchandise has been retained. It was redeveloped to cope with new demands and to be a distinctive gateway to enter the old city.

- Many religious, educational and cultural buildings have been preserved due to their heritage value and their function, modified to be compatible with the surrounding uses, in order to create a vibrant fabric.

- The areas surrounding the heritage core, especially from the south and south-east (Judaidat district) has been regarded as mixed uses, in addition to Al Safih area to the west, being regarded as a commercial area with a religious tourism stream. Wadi Al Salam cemetery limits the expansion of project from the north and north-east.

\section{Strategy 3: Building Heights}

According to the project reports, one of the biggest challenges in determining the appropriate heights of buildings is maintaining the urban fabric of the old city with the dominance of the shrine on the centre, therefore the proposed heights of buildings (figure11) as follows: 2 floors for the building surrounding the holy shrine, 4 floors for the next zone of mixed use, and up to 6 floors for the edges of the Al-Muheet street (mixed use).

\section{Strategy 4: Land Acquisition}

Based on the information mentioned in the regeneration proposal report, the total acquisition of land within the study area is around $\left(118,000 \mathrm{~m}^{2}\right)$. According to Dewan (2015) the acquisition policy follows five types as shown in figure (12) depending on the intended purpose, as follows:

Acquisition for expanding the visitors' area $(90 \mathrm{~m})$ : around the holy shrine from the north, east and south.

Acquisition for expansion of Zayn al-Abidin and Al-Sadiq streets (west): based on the Ataba expansion project.

Acquisition for expansion of roads: to provide the necessary spaces for infrastructure networks and to facilitate the entry of services and emergency vehicles.

Acquisition for developing the Grand Suq: to provide spaces for the market development.

\section{Strategy 5: Public Services:}

Based on the international and local standards that have been adopted in the regeneration proposal to calculate the needs for public services for the old city and depending on the estimated population for the target year 2030, there are clear shortages in the existing services and public facilities. Due to the limited availability of land 
within the project area, the development strategy proposed to provide those public services within available areas outside the historic city centre, as future expansion areas (Dewan, 2015, p.7).

\section{Strategy 6: Transportation system}

The public transport stations in the new regeneration proposal have been located around the old city at appropriate distances to enable the residents and visitors to reach the shrine zone in short distances by walking. Figure (13) shows the proposed locations of new public transport stations and the expected tourists' volume at the target year 2030. In addition, figure (14) shows the proposed pedestrian walkways network. According to Dewan (2015) these networks take into account the improvement of the entrance and exit routes, since many of the routes are used for different purposes at the same time, as well as providing a special path for emergency and services vehicles.



Figure 9. Heritage and historical buildings survey. Source: Dewan (2015, p.80)

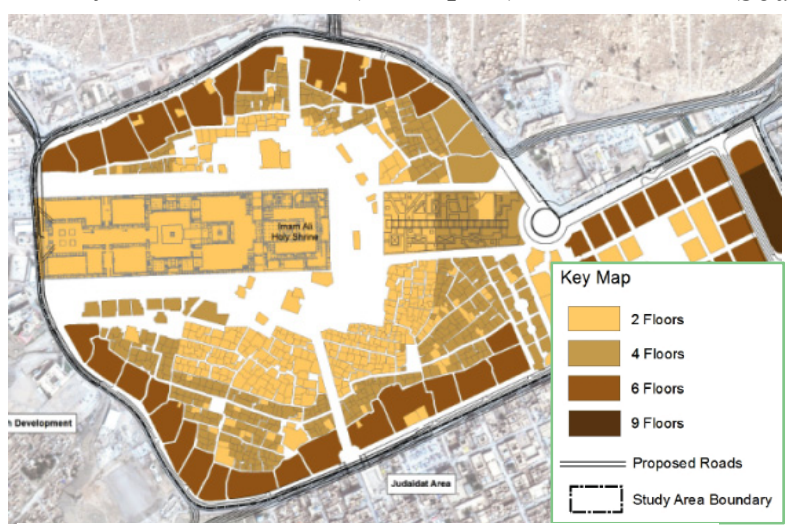

Figure 11. Proposed buildings heights. Source: Dewan $(2015$, p.12)

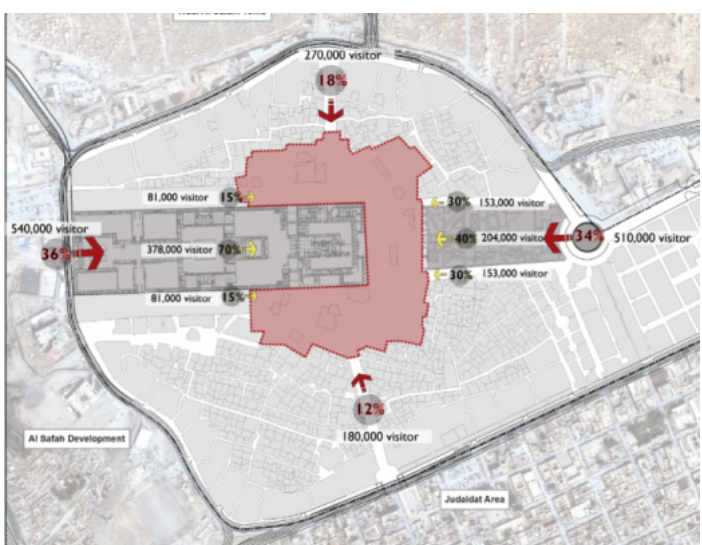

Figure 13. Expected tourists volume at the target year 2030. Source: Dewan (2015, p.23)



Figure 10. Proposed land uses plan inside the study area. Source: Dewan (2015, p.11)

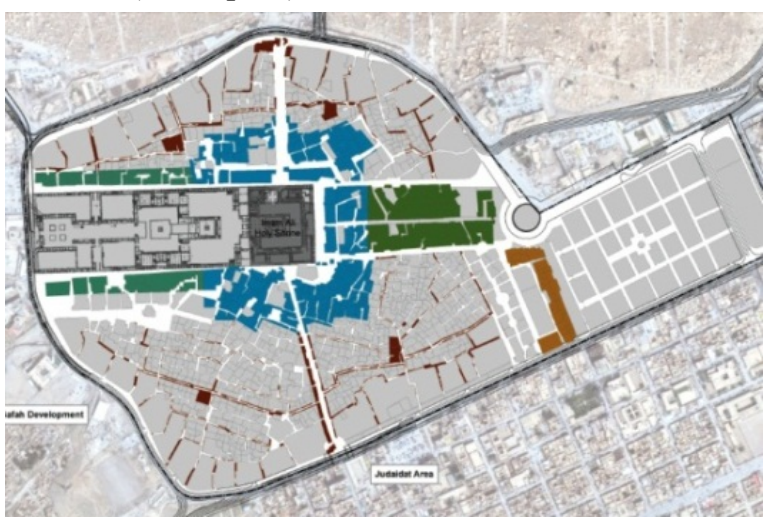

Figure 12. General acquisition map. Source: Dewan (2015, p.16)



Figure 14. Pedestrian walkways network.

Source: Dewan (2015) 


\subsubsection{Assessment of the Najaf Regeneration Project according to the Developed Strategy}

It is obvious from reviewing the existing literature about the case study, the lack of a comprehensive urban development policy that would guide regulations in line with the needs of the current socio-economic realities. Further, some of these regulations and guidelines may contradict the new regeneration programmes. The regeneration proposal for historic part of Najaf city was assessed according to the developed model of assessment strategy of the current study. The final form of the assessment strategy was included in the expert questionnaire survey. The questionnaire was sent to the respondents with brief details about the project in addition to the available maps and photos. The assessor was asked to evaluate the proposal's urban policies and design strategies, according to the design principles and the devised assessment indicators in order to determine the sustainability of the project and the extent of success in achieving the set of goals.

\section{Findings of Implementation and Case Study Analysis}

Suitability and applicability of the developed strategy for use at the local context was examined and an idea about current regeneration trends in Iraq was formed. The experts responded to the questionnaire and the discussion of analysis results are built on translation of the questionnaire results to qualitative description and demonstrated in the hierarchy according to the assessment criteria given in the developed model as shown in the following:

\section{Urban design principle: Character}

Performance criterion

Context

- Most of the respondents commented that with this effort of the consultant, it is not easy to judge the degree of success of this project regarding compatibility with surroundings due to the complex existing situation and multiple social, political and economic factors affecting the decision taking. But the general appearance gives a good impression about the future of the area if the project is realised and the proposal obtained a high score regarding this issue.

- Despite the fact that the historic city centre of Najaf had lost a considerable amount of its features, the consultant tried to incorporate the cultural and historical existing context, to integrate with the physical environment such as existing streets, buildings and infrastructure. Furthermore, the proposal showed good attempts at compatibility with surrounding social and economic activities.

\section{Performance criterion Detailed Design}

- A medium score was awarded to this criterion as some details of the external design such as elevation details, arches types etc. are not close to the local styles. The consultant tried to cope with the existing buildings and open spaces in aspects of visual appearance; however the building height surrounding the historical area faced criticism due to excessive height which disturbs the traditional central view of the shrine. Urban design principle: Continuity and enclosure

Performance criterion Layout

- The proposal obtained high scores regarding this criterion. The designers attempted to align routes of the new development with the desired existing lines and the buildings relate to a common building line, for two reasons, first the high real estate prices of the existing plots, second the wish of the designers to revitalise the traditional urban fabric of the city. In addition most of the streets, routes and open spaces in the old city are treated as pedestrian zones containing many community activities; this is supported by controlling the traffic by design and layout.

- Layout of blocks provides public spaces and green areas in addition to the private spaces-this was aided by profiting from existing vacant plots.

Performance criterion Privacy and Amenity

- The proposal was prepared for a distinguished historic and spiritual centre that is active 24 hours a day all year round, so this criterion was neutralised. The focus was on the provision of public services and facilities. Regarding privacy, after many changes in the land uses and social structure most of the building functions are turned to the public uses, therefore the privacy factors were also neutralised in the current assessment.

Urban design principle: Quality of the public realm

Performance criterion

Public Realm

- The public realm in this project was one of the most important requirements to consider in order to cope with the vast numbers of visitors to the city centre and there was a clear distinction between public, semi and private spaces. In this regard the proposal obtained a high score.

- Roads and open spaces are considered as an integral landscape element within the public realm design. Furthermore the designers attempted to benefit from the available spaces and routes to create enough spaces while at the same time avoiding the disruption of the existing traditional fabric 
- Due to the complexity in the regeneration site and lack of adequate land, the provision of enough car parking was a big challenge for the designers. The proposal attained medium score for this criterion, because there was no clear vision for parking facilities with maximum efficiency in the project. On the other hand, high quality and well-designed materials for street furniture were used, in order to integrate with the surrounding and enhance the sense of places.

Urban design principle: Ease of movement

Performance criterion

Inclusiveness and Connections

- A high score was given to this criterion. The proposed buildings reflect a positive impression to the passers and priorities are given to the walkways and pedestrian passage designs which connect to public transport in terms of location, width and material used.

- The proposed urban structure seems to have an attractive network of connected spaces and routes for pedestrians along with reasonable solutions for vehicles.

- Regarding the links of new layouts to the existing routes and places, the designer tried as much as possible to make use of these existing routes to create new networks.

Urban design principle: Legibility

Performance criterion Distinctiveness

- The designers tried to benefit from the existing situation of what was left of the old historic centre to enforce the identity of locality-routes and spaces. It is not easy to achieve such task after a long period of neglect of the traditional fabric and interventions of modern architecture. The buildings' design was taken into account to improve the legibility of place, in addition the proposal succeeded in presenting a layout from the existing buildings and landform features to create a memorable layout. According to these facts this aspect attained a good scoring point despite some remarks related to the treatment of open spaces.

Urban design principle: Adaptability

Performance criterion

Adaptability

- The project is to be implemented in a populous area, having a wide range of activities with expensive real estate prices, so the opportunities for future changes will be limited and need considerable resources. Furthermore, the building forms are already of a complex nature and designed for a particular use, therefore the possibility for future modifications would be restricted to some uses.

- In spite of designers attempts to rehabilitate distinguish properties for modern uses this criterion obtained medium scores with comments about the ratio of retained buildings to the total new construction area on-site.

Urban design principle: Diversity

Performance criterion

Variety

This criterion was awarded very good scoring. The reason for that is the nature of the city as a historical and vibrant centre containing a wide range of facilities and activities (social, cultural, commercial). Therefore the regeneration proposal just enhanced what is already present in the area.

Urban design principle: Efficiency

Performance criterion

Efficiency-green construction

- The historic city centre of Najaf is a very complex urban structure which encloses a mixture of uses and activities within a multi-layered infrastructure. Therefore, solving the urban problems in one step and for a long duration is hard to accomplish. The regeneration proposal reached a medium score for this criterion.

- The designers intended to make use of the potential of the high density of the city by providing adequate accessibility to public transport and sufficient landscape area that does not disturb the heritage fabric.

- According to the project reports, the designers took in consideration the incorporation of sustainable infrastructure such as drainage systems and waste management. The consumption of resources was not a priority, as the goal of the project was the creation of a luxurious style of design.

Urban design principle: Safety and Security

Performance criterion

Sense of safety

- The new design made use of the existing roads and paths that are already overlooked by public uses such as hotels, shops and offices or by residential units. So the sense of security was high for pedestrians and users. Furthermore public spaces are already secure because they contain mixed uses and some of these activities go on the whole 24 hours. Traffic is very limited in the centre of the city; therefore there is safe and undisturbed pedestrian movement. Based on these facts a good score was obtained here.

Urban design principle: Services

Performance criterion

Compactness

- This point aroused controversies among the respondents due to the fact that the proposal came up with many alternatives for public facilities and services. Overall, the criterion had a good score and most of the proposed public facilities were introduced in high quality design and located in the main axes which make them safe and attractive for users and visitors. Some indicators were difficult to grasp by the assessors because of the lack of respective data or drawings such as the facilities for disabled persons. 
Urban design principle: Green design

Performance criterion

Environmental improvement

The assessment of this criterion was not straightforward. In general, the assessors evaluated the available data and they justified that the project deserves a good score. The designers incorporated traditional architectural treatments such as courtyards, arcades and shaded elevations to provide amenity in the environment. In addition, the traditional narrow alleys and closed courtyards already offer protection and reduce the impact of the adverse climate conditions.

\section{Conclusions}

The main conclusions refer to and summarise potential elements of future strategies for the urban regeneration of historic cities in Iraq, strategies that combine heritage protection and socioeconomic development in an effort to improve the liveability and the vitality of the urban environment. The following points summarise the main study conclusions:

- The research process confirmed that sustainable development is the most appropriate trend for achieving urban regeneration to meet the needs of present and future generations.

- A lack of holistic research studying the interaction of sustainable development, urban regeneration and urban design at the Iraqi local level. Therefore, this study was an attempt to investigate those issues and their interface.

- The role of urban design in urban regeneration which leads to sustainable outcomes was clarified through the study processes.

- To illustrate the relationship between sustainable urban regeneration and urban design, the study developed an assessment strategy for assessing the extent to which these concepts are applied to local practices, and this assessment model can be regarded as the main achievement of the current research.

- The developed strategy can help the designers and stakeholders to evaluate the design quality and the performance of regeneration projects, and provide a tool to review and reform the urban regeneration policies or strategies in Iraqi cities.

- Even though some commented about the indicators of strategy, the respondents had confirmed the validity of the assessment indicators as elements of a measurement tool.

- At the local context the concepts of sustainability and urban regeneration are still in the beginning and many efforts are needed to improve the available knowledge about understanding and implementing these themes.

- More urban regeneration projects are expected to be implemented in Iraq in the future. Therefore, sustainable urban regeneration approaches should be established through in-depth investigations.

- Despite many changes in urban form, multiplication of development agencies and lack of a comprehensive urban development policy, the historic centre still plays a crucial role in shaping the core of the cities in Iraq.

- The process of this study can serve as a preliminary guide for the professionals to derive their own list of urban design considerations or assessment models.

- The medium to good scores in most of the assessment indicators reflect the evolution in redevelopment approaches at the local level and increasing attempts to adopt the principals and objectives of sustainable urban regeneration in Iraq.

- Evaluation of regeneration initiatives in the existing heritage built environment in Iraq help to answer the questions about the challenges facing the heritage values of the urban context in addition to evaluating the role of local heritage in achieving the cultural led regeneration approaches.

\section{References}

Biddulph, M. (2011). Urban Design, Regeneration and the Entrepreneurial City. Progress in planning, (76), 63103. https://doi.org/10.1016/j.progress.2011.08.001

CABE \& DETR (Department of Environment, Transport, and Regions). (2001). The value of urban design. London: Thomas Telford. Retrieved from http://www.designcouncil.org.uk/sites/default/files/asset/document/the-value-of-urban-design_0.pdf

CABE (Commission for Architecture and the Built Environment). (2003). The councillor's guide to urban design. London: CABE.

CABE. (2004). Creating successful masterplans: A guide for clients. London: CABE. Retrieved from http://webarchive.nationalarchives.gov.uk/20110118095356/http:/www.cabe.org.uk/files/creatingsuccessful-masterplans.pdf 
Chanan, G., West, A., Garratt, C., \& Humm, J. (1999). Regeneration and sustainable communities. London: Community Development Foundation.

Colantonio, A., \& Dixon, T. (2011). Urban regeneration \& social sustainability, Best practice from European cities (1st ed.). West Sussex: A John Wiley \& Sons, Ltd.

DETR (Department of the Environment, Transport and the Regions). (1998). Sustainability counts. London: HMSO.

DETR. (2000). By design: Urban design in the planning system: Towards better practice. London: Thomas Telford Ltd.

Devuyst, D. (2001). Introduction to sustainability assessment at the local level. In Devuyst, D., Hens, L., \& Lannoy, W. (Eds.), How green is the city? Sustainability assessment and the management of urban environments (pp. 1-36). New York, Columbia University Press. https://doi.org/10.7312/devu11802-intro

Dewan (Architects \& Engineers). (2010). Dewan awarded contracts for "urban renewal" of historic religious cities in Iraq. $\quad$ Retrieved from http:/www.dewan architects.com/2014web_backup/news_urban_renewal.html

Dewan. (2015). Urban renewal of the city centre of Najaf: Comprehensive master plan of the city centre of holy Najaf old city (stage five). Baghdad: General directorate of physical planning, Ministry of Municipalities and public Works.

Dumper, M. (2007). Najaf. In Dumper, M., \& Stanley, B. (Eds.), Cities of the Middle East and North Africa: A historical encyclopedia (pp.268-271). California, ABC-CLIO, Inc.

Ewing, R., Clemente, O., Handy, S., Brownson, R., \& Winston, E. (2005). Identifying and measuring urban design qualities related to walkability. Final report prepared for the; Active Living Research Program of the Robert Wood Johnson Foundation. Retrieved from http://smartgrowth.umd.edu/assets/documents/research/ewingclementehandyetal_walkableurbandesign_200 5.pdf

GBCA (Green Building Council of Australia) \& ISCA (Infrastructure Sustainability Council of Australia). (2011). Creating places for people: An urban design protocol for Australian cities. Available from http://urbandesign.org.au/downloads/

Hemphill, L., Berry, J., \& McGreal, S. (2004). An Indicator-Based Approach to Measuring Sustainable Urban Regeneration Performance: Part 1, Conceptual Foundations and Methodological Framework. Urban Studies, 41(4), 725-755. https://doi.org/10.1080/0042098042000194089

Holden, M. (2006). Urban Indicators and the Integrative Ideals of Cities. Cities, 23(3), 170-183. https://doi.org/10.1016/j.cities.2006.03.001

Jones, P., \& Evans, J. (2008). Urban regeneration in the UK. London, SAGE.

Kühn, M., \& Liebmann, H. (2012). Urban Regeneration-Strategies of Shrinking Cities in Eastern Germany. Journal DIE ERDE, 143, (1-2), 135-152. Retrieved from http://www.die-erde.org/index.php/dieerde/article/download/26/22.

Lee, G. K. L. (2008). Sustainable urban renewal model for a high density city-Hong Kong (Doctoral dissertation). Hong Kong Polytechnic University, Hong Kong.

Llewellyn, D., Pike, O., Durney, M., Design for Homes \& Zero G. (2008). Urban design manual a best practice guide: A companion document to the draft planning guidelines on sustainable residential development in urban areas. Dublin: Department of Environment, Heritage and Local Government.

Llewelyn, D., \& Baxter, A. (2007). Urban design compendium (2nd ed.). London: English Partnerships.

Mrdenovic, T. (2011). Integrative Urban Design in Regeneration-Principles for Achieving Sustainable Places. Journal of Applied Engineering Science, 9(2), 196, 305-316. Retrieved from http://www.researchgate.net/publication/267963211_INTEGRATIVE_URBAN_DESIGN_IN_REGENERA TION_-PRINCIPLES_FOR_ACHIEVING_SUSTAINABLE_PLACES

NHDC (North Hertfordshire District Council). (2007). North Hertfordshire urban design assessment: district assessment (Final report). North Hertfordshire: NHDC.

RBC (Rochdale Borough Council). (2007). Oldham and Rochdale urban design guide: Supplementary planning document. Rochdale: RBC. Retrieved from http://www.rochdale.gov.uk/pdf/2008-09-12-urban-designguide.pdf

Roberts, P., \& Sykes, H. (2000). Urban regeneration: A Handbook. London: Sage. 
Rosales, N. (2010). Towards a design of sustainable cities: Incorporating sustainability indicators in urban planning. Proceeding of Sustainability indicators in urban planning, 46th ISOCARP Congress. Retrieved from http://www.isocarp.net/data/case_studies/1715.pdf

SBE (School of the Built Environment-Napier University). (2005). Compendium: Handbook 3: Sustainable urban regeneration and its assessment. Edinburgh: SBE. Retrieved from http://www.luda project.net/compendium/handbook3.pdf

SEP (Science for Environment Policy). (2015). Indicators for sustainable cities. In-depth report 12. Produced for the European Commission DG Environment by the Science Communication Unit, UWE, Bristol. Retrieved from http://ec.europa.eu/science-environment-policy

Tabbaa, Y., \& Mervin, S. (2014). Najaf the gate of wisdom. Paris: UNESCO.

Tallon, A. (2013). Urban regeneration in the UK (2nd ed). Oxford: Routledge: Taylor \& Francis Group.

Wansborough, M., \& Mageean, A. (2000). The Role of Urban Design in Cultural Regeneration. Journal of Urban Design, 5(2), 181-197. https://doi.org/10.1080/713683962

\section{Appendix A}

The final structure of the sustainable urban regeneration assessment strategy which relies on urban design principles, criteria and indicators with their corresponding point scoring system. Source: Author elaboration

\begin{tabular}{|c|c|c|c|c|}
\hline \multicolumn{5}{|c|}{ Project details } \\
\hline $\begin{array}{c}\text { Urban } \\
\text { design } \\
\text { principles }\end{array}$ & $\begin{array}{l}\text { Performan } \\
\text { ce criteria }\end{array}$ & $\begin{array}{l}\text { Assessment indicators (Positive impacts ) } \\
\text { represent the positive performance of regeneration scheme }\end{array}$ & $\begin{array}{l}\text { Guideline: } \\
\text { Evaluation Point } \\
\text { of } 1-5 \text {, of indivi } \\
1=\text { not at all succ } \\
5=\text { very successfi }\end{array}$ & $\begin{array}{l}\text { llocated on a scale } \\
\text { ual criteria. } \\
\text { sful } \\
\text { y }\end{array}$ \\
\hline \multirow{14}{*}{$\begin{array}{l}\text { Character } \\
\text { Sense of } \\
\text { place and } \\
\text { history }\end{array}$} & \multirow{6}{*}{ Context } & The regeneration scheme seems to: & & \multirow{5}{*}{$\begin{array}{l}\text { Score weight of } \\
\text { criterion } \\
\text { Either succeed in } 1 \\
\text { indicator } \\
\square 1 \text { point } \\
\text { Any } 2 \text { indicator } \\
\square 2 \text { points } \\
\text { Any } 3 \text { indicator } \\
\square 3 \text { points } \\
\text { Any } 4 \text { indicator } \\
\square \quad 4 \text { points } \\
\text { All or above } \\
\square 5 \text { points }\end{array}$} \\
\hline & & $\begin{array}{l}\text { Ind.1: Positively contribute to the character and identity of the } \\
\text { surrounding neighbourhood properties. (Llewellyn et al., 2008; } \\
\text { RBC, 2007). }\end{array}$ & $\square \square \square \square \square$ & \\
\hline & & $\begin{array}{l}\text { Ind.2: Incorporate the heritage, culture and historical context of } \\
\text { surrounding communities and places (CABE, 2003; RBC, 2007; } \\
\text { GBCA \& ISCA, 2011). }\end{array}$ & $\square \square \square \square \square$ & \\
\hline & & $\begin{array}{l}\text { Ind.3: Integrate with the surrounding physical environment, } \\
\text { including its topography, biodiversity, landscape and views, } \\
\text { existing buildings, streets and infrastructure (DETR, 2000; } \\
\text { Llewellyn et al., 2008; Lee, 2008; GBCA \& ISCA, 2011). }\end{array}$ & $\square \square \square \square \square$ & \\
\hline & & $\begin{array}{l}\text { Ind.4: Be compatible with the surrounding social and economic } \\
\text { activities and the amenity enjoyed by users (Llewellyn et al., 2008; } \\
\text { GBCA \& ISCA, 2011). }\end{array}$ & $\square \square \square \square \square$ & \\
\hline & & \multicolumn{3}{|l|}{ Result } \\
\hline & \multicolumn{4}{|l|}{ Comments } \\
\hline & \multirow{6}{*}{$\begin{array}{l}\text { Detailed } \\
\text { Design }\end{array}$} & In the regeneration scheme: & & \\
\hline & & $\begin{array}{l}\text { Ind.1: The materials and external design make a positive } \\
\text { contribution to the locality (Llewellyn et al., 2008). }\end{array}$ & $\square_{1} \square_{2} \square \square_{4} \square_{5}$ & \multirow{4}{*}{$\begin{array}{l}\text { Score weight of } \\
\text { criterion } \\
\text { Either succeed in } 1 \\
\text { indicator } \\
\square 1 \text { point } \\
\text { Any } 2 \text { indicator } \\
\square 2 \text { points } \\
\text { Any } 3 \text { indicator } \\
\square 3 \text { points } \\
\text { Any } 4 \text { indicator } \\
\square \quad 4 \text { points } \\
\text { All or above } \\
\square 5 \text { points }\end{array}$} \\
\hline & & $\begin{array}{l}\text { Ind.2: Satisfactory visual appearance of the properties in terms of } \\
\text { appropriate height and bulk of individual buildings (Lee, 2008). }\end{array}$ & $\square \square \square \square \square$ & \\
\hline & & $\begin{array}{l}\text { Ind.3: Design of the buildings and public space will facilitate easy } \\
\text { use and regular maintenance (RBC, 2007), (Llewellyn et al., 2008). }\end{array}$ & $\square \square_{2} \square \square \square$ & \\
\hline & & $\begin{array}{l}\text { Ind.4: Acceptable density of development within regeneration site } \\
\text { in terms of Plot Ratio ( } \mathrm{PR}=\text { total gross building floor area / total } \\
\text { site area to be regenerate) (Lee, 2008). }\end{array}$ & $\square \square \square \square \square \square$ & \\
\hline & & \multicolumn{3}{|l|}{ Result } \\
\hline & Comments & & & \\
\hline \multirow{4}{*}{  } & \multirow{4}{*}{ Layout } & The regeneration scheme shows: & & \\
\hline & & $\begin{array}{l}\text { Ind.1: Layout ensures that there is continuity in the frontages of } \\
\text { streets and spaces through buildings relating to a common building } \\
\text { line, street blocks or alongside public spaces; to create permeable } \\
\text { routes and define the street (DETR, 2000; RBC, 2007; Llewellyn } \\
\text { et al., 2008). }\end{array}$ & $\square \square \square \square \square \square$ & \multirow{3}{*}{$\begin{array}{l}\text { Score weight of } \\
\text { criterion } \\
\text { Either succeed in } 1 \\
\text { indicator } \\
\square 1 \text { point } \\
\text { Any } 2 \text { indicator } \\
\square 2 \text { points } \\
\text { Any } 3 \text { indicator } \\
\square 3 \text { points }\end{array}$} \\
\hline & & $\begin{array}{l}\text { Ind.2: The layout focuses activities on the streets by creating } \\
\text { active frontages with front doors directly serving the street } \\
\text { (Llewellyn et al., 2008) }\end{array}$ & $\square \square \square \square \square \square$ & \\
\hline & & $\begin{array}{l}\text { Ind.3: The streets are designed as places, helping to create a } \\
\text { hierarchy of space with less busy routes shared by pedestrians, }\end{array}$ & $\square \square \square \square \square \square$ & \\
\hline
\end{tabular}




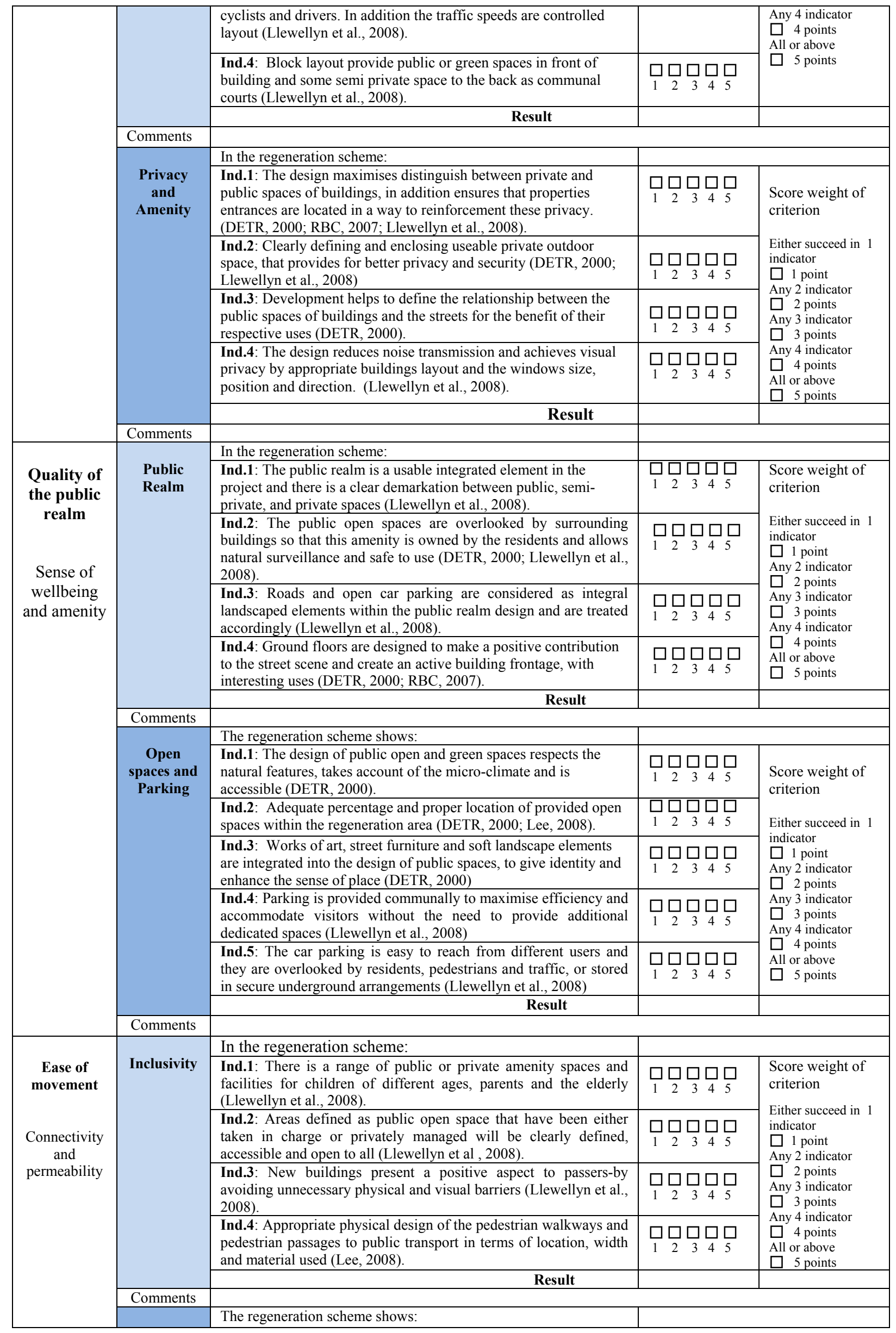




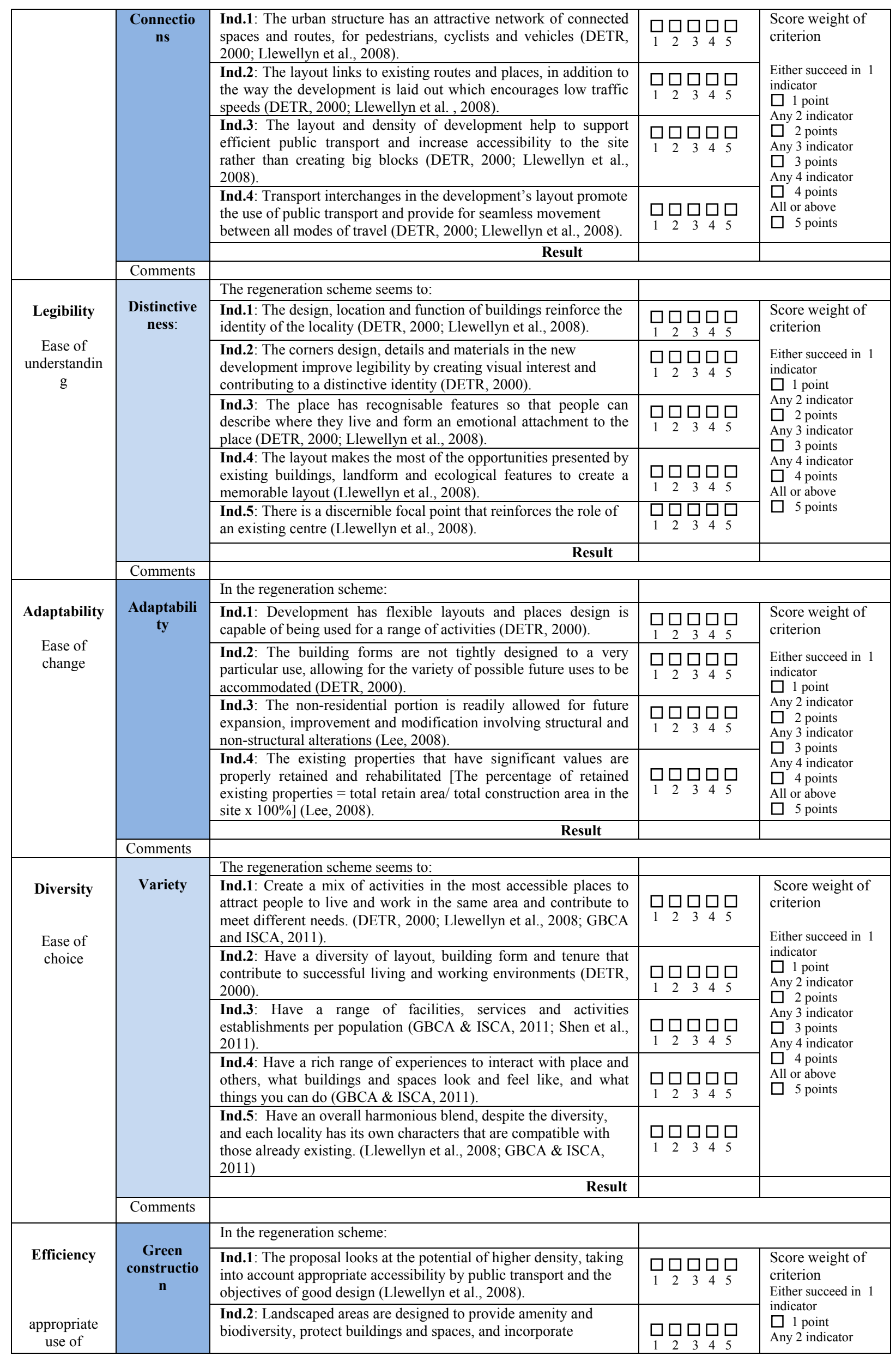




\begin{tabular}{|c|c|c|c|c|}
\hline \multirow[t]{5}{*}{ resources } & & sustainable urban drainage systems (Llewellyn et al., 2008). & & \multirow{4}{*}{$\begin{array}{l}\quad 2 \text { points } \\
\text { Any } 3 \text { indicator } \\
\square \quad 3 \text { points } \\
\text { Any } 4 \text { indicator } \\
\square \quad 4 \text { points } \\
\text { All or above } \\
\square \quad 5 \text { points }\end{array}$} \\
\hline & & $\begin{array}{l}\text { Ind.3: The scheme brings a redundant building or derelict site back } \\
\text { into productive use (Llewellyn et al., 2008). }\end{array}$ & $\underset{1}{\square \square} \underset{3}{\square} \square$ & \\
\hline & & $\begin{array}{l}\text { Ind.4: The adopted construction practices in the project, can } \\
\text { effectively minimize the consumption of natural resources and use } \\
\text { them in an efficient way (Lee, 2008) }\end{array}$ & \multirow[t]{2}{*}{$\underset{1}{\square} \square \underset{3}{\square} \square$} & \\
\hline & & Result & & \\
\hline & Comments & & & \\
\hline \multirow{8}{*}{$\begin{array}{l}\text { Safety and } \\
\text { Security }\end{array}$} & \multirow{7}{*}{$\begin{array}{l}\text { Sense of } \\
\text { safety }\end{array}$} & Regeneration proposals designed to: & & \\
\hline & & $\begin{array}{l}\text { Ind.1: Ensure design of roads and paths that are safe and } \\
\text { convenient for all citizens to walk or walk to the nearest public } \\
\text { transport facilities or ride their bikes (Lee, 2008; GBCA \& ISCA, } \\
\text { 2011; RBC, 2007). }\end{array}$ & 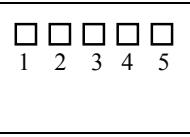 & \multirow{5}{*}{$\begin{array}{l}\text { Score weight of } \\
\text { criterion } \\
\text { Either succeed in } 1 \\
\text { indicator } \\
\square 1 \text { point } \\
\text { Any } 2 \text { indicator } \\
\square 2 \text { points } \\
\text { Any } 3 \text { indicator } \\
\square 3 \text { points } \\
\text { Any } 4 \text { indicator } \\
\square 4 \text { points } \\
\text { All or above } \\
\square 5 \text { points }\end{array}$} \\
\hline & & $\begin{array}{l}\text { Ind.2: Ensure all routes and open spaces are well overlooked by } \\
\text { buildings to avoid creating hiding places and segregating } \\
\text { pedestrians, cyclists and vehicles (RBC, 2007; GBCA \& ISCA, } \\
\text { 2011). }\end{array}$ & $\underset{1}{\square} \square \square_{3} \square$ & \\
\hline & & $\begin{array}{l}\text { Ind.3: Concentrate the activity along a network of pedestrian- } \\
\text { friendly key routes and public spaces so that these can be "self- } \\
\text { policing" (RBC, 2007). }\end{array}$ & $\square \underset{1}{\square} \square \underset{3}{\square} \square$ & \\
\hline & & $\begin{array}{l}\text { Ind.4: Ensure car parks and cycle parking areas are accessible with } \\
\text { secure and visible entrances and exits (RBC, 2007). }\end{array}$ & $\underset{1}{\square} \square \square_{3} \square \square$ & \\
\hline & & $\begin{array}{l}\text { Ind.5: Provide a clear distinction between the publicly accessible } \\
\text { streets or space and private space of individual or groups of } \\
\text { buildings (RBC, 2007). }\end{array}$ & $\square \square_{2} \square_{3} \square \square_{5}$ & \\
\hline & & \multirow{2}{*}{\multicolumn{2}{|c|}{ Result }} & \\
\hline & Comments & & & \\
\hline \multirow{7}{*}{$\begin{array}{l}\text { Services } \\
\text { provision }\end{array}$} & \multirow{6}{*}{$\begin{array}{l}\text { Compactn } \\
\text { ess }\end{array}$} & Regeneration proposals designed to: & & \\
\hline & & $\begin{array}{l}\text { Ind.1: Consider the factors of distance, comfort and safety when } \\
\text { locating the public facilities (Lee, 2008). }\end{array}$ & $\underset{1}{\square} \square \square_{3} \square \square_{5}$ & \multirow{4}{*}{$\begin{array}{l}\text { Score weight of } \\
\text { criterion: } \\
\text { Either succeed in } 1 \\
\text { indicator } \\
\square 1 \text { point } \\
\text { Any } 2 \text { indicator } \\
\square 2 \text { points } \\
\text { Any } 3 \text { indicator } \\
\square 3 \text { points } \\
\text { Any } 4 \text { indicator } \\
\square 4 \text { points } \\
\text { All or above } \\
\square 5 \text { points }\end{array}$} \\
\hline & & $\begin{array}{l}\text { Ind.2: Provide access to the public facilities in the residential } \\
\text { development 'that are essential to the daily necessity of } \\
\text { community' can be found within } 500 \mathrm{~m} \text { in the regeneration project } \\
\text { (Lee, 2008; SCI, 2012). }\end{array}$ & $\underset{1}{\square} \square \square_{3} \square$ & \\
\hline & & $\begin{array}{l}\text { Ind.3: Provide accessible design and adequate facilities for the } \\
\text { people regardless of age and physical abilities (Lee, 2008). }\end{array}$ & $\begin{array}{l}\square \square \\
1\end{array}$ & \\
\hline & & $\begin{array}{l}\text { Ind.4: Provide local services and deal with the volume of } \\
\text { generated solid waste (Rosales, 2010; SEP, 2015). }\end{array}$ & $\underset{1}{\square} \square_{3} \square \square_{5}$ & \\
\hline & & \multirow{2}{*}{\multicolumn{2}{|c|}{ Result }} & \\
\hline & Comments & & & \\
\hline \multirow{8}{*}{$\begin{array}{c}\begin{array}{c}\text { Green } \\
\text { design }\end{array} \\
\text { Minimising } \\
\text { the impact on } \\
\text { our } \\
\text { environment }\end{array}$} & \multirow{7}{*}{$\begin{array}{l}\text { Environme } \\
\text { ntal } \\
\text { improveme } \\
\text { nt }\end{array}$} & Regeneration proposals designed to: & & \\
\hline & & $\begin{array}{l}\text { Ind.1: Ensure that the layout and orientation of buildings benefits } \\
\text { from passive solar gain for natural heating and use natural } \\
\text { ventilation to reduce the mechanical requirements (RBC, 2007; } \\
\text { Lee, 2008; Llewellyn et al., 2008). }\end{array}$ & $\underset{1}{\square} \square_{3} \square \square$ & \multirow{4}{*}{$\begin{array}{l}\begin{array}{l}\text { Score weight of } \\
\text { criterion }\end{array} \\
\text { Either succeed in } 1 \\
\text { indicator } \\
\square 1 \text { point } \\
\text { Any } 2 \text { indicator } \\
\square 2 \text { points } \\
\text { Any } 3 \text { indicator } \\
\square 3 \text { points } \\
\text { Any } 4 \text { indicator } \\
\square 4 \text { points } \\
\text { All or above } \\
\square 5 \text { points }\end{array}$} \\
\hline & & $\begin{array}{l}\text { Ind.2: locate buildings where they are least exposed to the chilling } \\
\text { effect of prevailing winds, using topography, other buildings and } \\
\text { tree belts to provide shelter (RBC, 2007). }\end{array}$ & $\underset{1}{\square} \underset{1}{\square} \underset{3}{\square} \square$ & \\
\hline & & $\begin{array}{l}\text { Ind.3: reduce the potential for overheating on south facing facades } \\
\text { and the need for mechanical cooling (through appropriate window } \\
\text { sizes or screens or planting to provide shading) (RBC, 2007) }\end{array}$ & $\square \square \square_{3} \square \square$ & \\
\hline & & $\begin{array}{l}\text { Ind.4: provide for natural daylight and sunlight to illuminate the } \\
\text { interior of buildings and reducing the need for artificial lighting } \\
\text { (RBC, 2007) }\end{array}$ & $\underset{1}{\square} \square_{3} \square \square_{5}$ & \\
\hline & & $\begin{array}{l}\text { Ind.5: Gardens and public spaces are laid out to exploit the best } \\
\text { solar orientation (Llewellyn et al., 2008). }\end{array}$ & $\square \square \square \underset{1}{\square \square} \square$ & \\
\hline & & Result & & \\
\hline & Comments & & & \\
\hline
\end{tabular}

\section{Copyrights}

Copyright for this article is retained by the author(s), with first publication rights granted to the journal.

This is an open-access article distributed under the terms and conditions of the Creative Commons Attribution license (http://creativecommons.org/licenses/by/4.0/). 